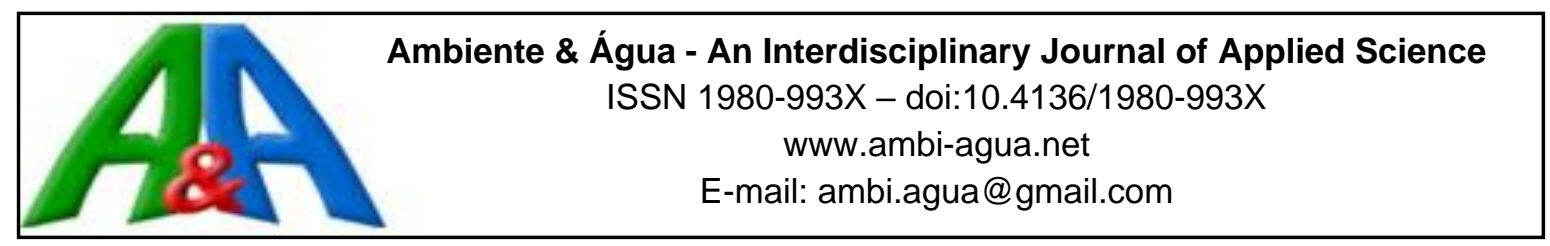

\title{
Compostagem e educação ambiental: visão da comunidade escolar avaliada pelo método da análise de conteúdo
}

\author{
doi:10.4136/ambi-agua.1901 \\ Received: 03 Oct. 2016; Accepted: 01 Dec. 2016

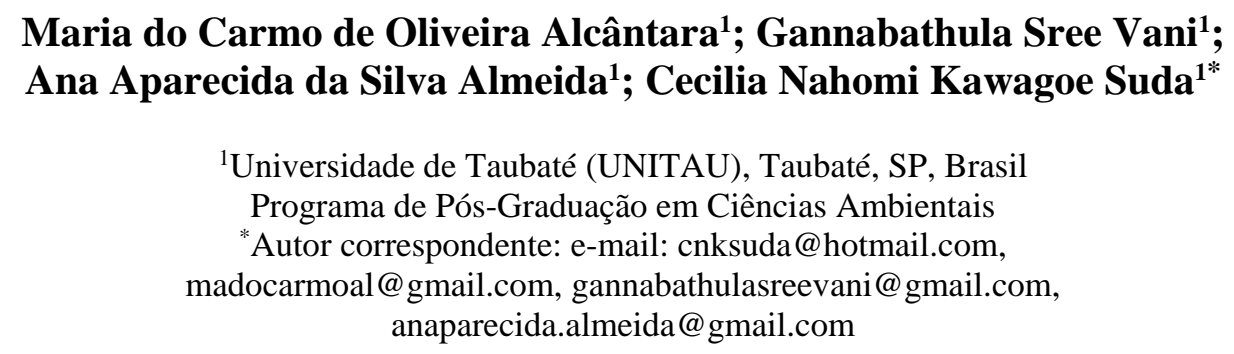

\section{RESUMO}

Um dos maiores problemas ambientais dos nossos dias é a enorme quantidade de resíduos produzidos diariamente. Na Escola de Ensino Fundamental e Médio Tenente Rêgo Barros (ETRB), na cidade de Belém (PA), cerca de $3 \mathrm{t}$ de matéria seca por semestre são produzidas em sua área verde. Para dar um destino ambientalmente correto e formar educandos com responsabilidade ambiental, foi proposta a elaboração de um projeto interdisciplinar e transversal, que utiliza a compostagem como uma metodologia de educação ambiental e de aprendizagem significativa. O presente trabalho teve como objetivos analisar o interesse dos orientadores pedagógicos, professores, funcionários e pais de alunos da ETRB, prever o grau de envolvimento dos docentes e o nível de colaboração de pais e funcionários sobre a implantação desse projeto de compostagem. O estudo utilizou dois instrumentos para a coleta dos dados, um questionário e a produção de um desenho livre, o qual foi submetido ao método de análise de conteúdo. Os resultados obtidos indicaram que a comunidade é favorável à execução do projeto, mas somente $20 \%$ dos professores mencionaram a utilidade didática da composteira. Cerca de $70 \%$ da comunidade escolar enfatizou a produção de adubo, sugerindo que a composteira é considerada como um fim em si, para solucionar o problema dos resíduos orgânicos da escola. A compostagem foi também considerada uma atividade restrita à disciplina de Ciências para a maioria dos professores e funcionários. Cabe, portanto, maior discussão e reflexão entre os professores, sobre a interdisciplinaridade e a transversalidade do projeto, para que se alcancem os objetivos da educação ambiental.

Palavras-chave: desenho, educação ambiental, projeto interdisciplinar.

\section{Compost formation as the theme of a pedagogical project in environmental education: vision of the school community as evaluated by content analysis}

\section{ABSTRACT}

One of the major environmental problems today is the large quantity of residues produced daily. In the elementary and secondary schools, Tenente Rêgo Barros (ETRB), in 
the city of Belém (PA), about 3 tons of dry material are produced each semester in the schools' green spaces. To dispose of this material in an environmentally friendly manner and to educate the pupils about environmental responsibility, an interdisciplinary and transversal project has been developed. The project uses composting as a method of environmental education and meaningful learning. This work aims to analyse the interests of pedagogical advisors, teachers, school employees and the parents of ETRB students, to examine the degree to which academic staff are involved. The study used two instruments to collect the data, a questionnaire and a freehand drawing subjected to content analysis. The results indicate that the community is in favor of the project but only $20 \%$ of the teachers could see the educative utility of the compost formation. About $70 \%$ of the school community saw the production of organic fertilizer as an end in itself and as a solution for the disposal of organic residue. Most of the faculty and employees saw the formation of compost as being restricted to a scientific subject. Hence, what is needed is a discussion by the teachers on the interdisciplinary and transversal nature of the compost formation to attain the objective of environmental education.

Keywords: environmental education, free hand drawing, interdisciplinary project.

\section{INTRODUÇÃO}

Um dos grandes problemas ambientais causado pelas sociedades humanas é, atualmente, a enorme quantidade de resíduos produzidos diariamente. As escolas são geradoras de resíduos e o seu destino final precisa ser colocado em questão, pois ainda há casos de escolas que os dispõem em vazadouros a céu aberto, contribuindo com o agravamento da problemática ambiental.

Esta realidade contrasta com a missão da escola, que seria a formação de cidadãos conscientes, capazes de atuarem na realidade sócioambiental visando o bem estar de todos neste planeta (Brasil, 1998, p. 20). Diante deste contraste, cabe à escola buscar novos caminhos de formação e informação que ajude aos educandos desenvolverem novas maneiras de relacionarem-se com o ambiente.

A Educação Ambiental (EA), neste contexto, desponta como possibilidade de mudança. De fato, em recomendações, decisões e tratados internacionais, a EA é considerada uma maneira indispensável para desenvolver formas sustentáveis de interação da humanidade com a natureza e solucionar problemas ambientais (Brasil, 1997a, p. 22). Nos Parâmetros Curriculares Nacionais (PCN), a educação ambiental é considerada um tema transversal, cuja abordagem recomendada é a interdisciplinar e integrada. A interdisciplinaridade diz respeito a uma abordagem dos objetos de conhecimento, guiada pelos saberes de um grupo de especialistas das diferentes áreas do conhecimento; já a transversalidade procura estabelecer na prática educativa uma relação entre aprender na realidade (dos conhecimentos teoricamente sistematizados) e da realidade, ou seja, sobre as questões da vida real (Brasil, 1997b).

A Escola de Ensino Fundamental e Médio Tenente Rêgo Barros, em Belém do Pará, local deste estudo, ocupa uma área de $52184 \mathrm{~m}^{2}$, com uma ampla área verde de $23198 \mathrm{~m}^{2}$, onde é produzido um grande volume de resíduos vegetais. Estes são destinados ao aterro sanitário ou à queima, na área externa da escola. Acredita-se que o desenvolvimento de um projeto pedagógico que inclua a problemática dos resíduos orgânicos vegetais, poderá contribuir para agregar e integrar conhecimentos de diversas áreas e permitirá aos estudantes vivenciarem, na prática, uma atitude que diminui o descarte de lixo e a degradação ambiental. Para isso, a formação de composteiras poderia constituir uma estratégia adequada para um projeto de EA nesta escola. 
A compostagem tem sido realizada em algumas escolas no Brasil. No caso de uma escola de São José do Rio Preto (SP), essa atividade propiciou um aprendizado interdisciplinar, que envolveu Matemática e Ciências (Sanches et al., 2006). Outro estudo foi realizado por Mello Filho (2014), em duas escolas localizadas no município de Pinhais (PR), em que comparou três tipos de composteiras com a finalidade de verificar qual delas se adaptava melhor à realidade destas escolas. O projeto desenvolvido numa escola situada em Outeiro, município de Belém (PA), objetivou a redução dos resíduos orgânicos vegetais produzidos na área externa da escola e adotar a técnica da compostagem como ferramenta para o processo de aprendizagem dos alunos do curso técnico em meio ambiente (Both e Senna, 2009).

Para que um projeto pedagógico que envolva a compostagem seja desenvolvido é necessária a participação de toda a comunidade escolar: docentes, discentes, funcionários, pais ou responsáveis. Os pais de alunos são importantes nesse processo, por quanto a ação negativa deles poderia representar uma série de restrições à participação dos filhos com os mais variados argumentos, tais como: suja as vestimentas, é anti-higiênico com risco à saúde, etc. Os funcionários da limpeza escolar, por outro lado, poderiam argumentar que esse tipo de atividade suja as várias dependências da escola, pois os alunos transitariam em vários locais após o manuseio de terra. Portanto, uma das etapas fundamentais para viabilização do projeto é o planejamento, que deve ser fruto da reflexão quanto aos objetivos pedagógicos, meios para que eles sejam atingidos e os resultados esperados. Essa reflexão precisa levar em conta as várias expectativas, temores, dificuldades e resistências para a execução do projeto dentro da comunidade escolar. Portanto, esta pesquisa objetivou realizar uma análise do interesse dos diferentes segmentos da comunidade escolar, prever o grau de envolvimento dos docentes e o nível de colaboração de pais e funcionários neste projeto interdisciplinar de compostagem. $\mathrm{O}$ resultado dessa análise poderá nortear o planejamento do projeto pedagógico para que a sua implantação ocorra de modo satisfatório para toda comunidade escolar.

\section{PROCEDIMENTOS METODOLÓGICOS}

\subsection{Local da pesquisa}

A pesquisa foi realizada na Escola de Ensino Fundamental e Médio Tenente Rêgo Barros (ETRB), localizada na Av. Júlio César s/n, no bairro do Souza, CEP: 66.613-010, na cidade de Belém (PA).

\subsection{Coleta de dados}

Os dados foram coletados durante o ano de 2015, tendo participado da pesquisa 49 membros da comunidade escolar, sendo 15 professores de diferentes níveis de ensino, 6 funcionários, 3 orientadores pedagógicos e 25 pais de alunos. Esses números representaram aproximadamente $10 \%$ dos professores, $10 \%$ dos funcionários, $30 \%$ dos orientadores pedagógicos e $2 \%$ dos pais de alunos da escola. A proporção de orientadores pedagógicos foi maior em relação aos demais, mas isso foi devido ao seu pequeno número total na escola (10). Os participantes deste estudo foram convidados pessoalmente pela pesquisadora e não houve qualquer tipo de seleção entre os interessados na participação.

Foram utilizados dois instrumentos metodológicos para a coleta de dados: a) um questionário e b) a produção de um desenho. O questionário utilizado contou com cinco questões abertas (Quadro 1), cujas respostas podiam ser elaboradas pelos sujeitos com as suas próprias palavras, a partir de uma formulação pessoal (Severino, 2007). O questionário foi respondido e os desenhos foram feitos nas dependências da escola. Os encontros ocorreram de forma individualizada na maioria das vezes, entretanto, quando os participantes foram atendidos em duplas, não houve interação entre eles. 
No ato da coleta de dados, primeiramente, informou-se aos participantes sobre os objetivos e a metodologia da pesquisa, bem como os benefícios da mesma para toda a comunidade escolar. Em seguida, os participantes assinaram o termo de consentimento livre e esclarecido, concordando com a divulgação dos resultados, sem a identificação dos sujeitos. Após a assinatura desse termo, a pesquisadora ratificou que seriam adotados dois instrumentos para a coleta de dados - um questionário e a produção de um desenho. Sobre o desenho foi esclarecido que na análise do mesmo, o foco não seria o seu valor artístico, mas os elementos constituintes de cada um deles. Depois de responderem ao questionário, foi solicitado aos participantes que "faça um desenho demonstrando como você imagina uma composteira na escola."

A pesquisa foi autorizada pelo Comitê de Ética em Pesquisa da Universidade de Taubaté (CAAE:45392615.9.0000.5501, parecer 1.127.398).

Quadro 1. Questões do questionário respondido pelos participantes da pesquisa.

1. O que é composteira?

\section{Questões}

2. Como você montaria uma composteira na escola?

3. O que você acha que pode ser feito com a composteira?

4. Você acha que a composteira poderia ser utilizada nas aulas? De que modo?

5. Você acha que a composteira traria algum inconveniente para você, os alunos ou a escola?

\subsection{Análise dos dados}

As respostas dos participantes ao questionário foram analisadas quanto ao seu nível de conhecimento a respeito da composteira, à sua receptidade à ideia de haver composteiras na escola e à sua percepção de uma utilidade didática deste recurso. As respostas foram agrupadas de acordo com a similaridade dos conteúdos para posterior análise quantitativa.

A análise dos desenhos foi realizada de acordo com o método da análise de conteúdo segundo Bardin (2011). A leitura do desenho foi feita considerando-se o seu sentido denotativo (sentido próprio ou literal) e conotativo (sentido figurado) das cenas produzidas pelos participantes. Assim, de acordo com os elementos (temas) presentes em cada um dos desenhos produzidos pelos participantes, foram elaboradas três categorias (Quadro 2). Essas categorias foram analisadas quantitativamente.

Quadro 2. Categorias definidas pelos temas presentes nos desenhos feitos pelos participantes da pesquisa.

\begin{tabular}{|ll|}
\hline \multicolumn{1}{|c|}{ Categorias } & \multicolumn{1}{c|}{ Temas presentes } \\
Conhecimento sobre a & $\begin{array}{l}\text { tipo de composteira; locais onde a composteira foi } \\
\text { representada; os resíduos representados na composteira; } \\
\text { presença de animais relacionados à decomposição orgânica } \\
\text { e referências ao chorume. }\end{array}$ \\
$\begin{array}{l}\text { Composteira como solução } \\
\text { ambientalmente correta para os } \\
\text { resíduos orgânicos }\end{array}$ & $\begin{array}{l}\text { ambientes organizados e limpos; casas/escolas nas quais há } \\
\text { geração de resíduos, podendo haver presença da } \\
\text { composteira no mesmo desenho }\end{array}$ \\
$\begin{array}{l}\text { Compostagem na atividade } \\
\text { escolar (Educação Ambiental) }\end{array}$ & $\begin{array}{l}\text { trabalhadores especializados em alunos, professores, pais de alunos e de } \\
\text { proximidades da composteira, horta e jardins ou em áreas } \\
\text { arborizadas da escola. }\end{array}$ \\
\hline
\end{tabular}




\section{RESULTADOS E DISCUSSÃO}

\subsection{Análise do questionário}

Com relação ao questionário, as perguntas 1 e 2 (Quadro1) procuraram avaliar o grau de conhecimento da comunidade escolar sobre a composteira. As respostas à essas perguntas foram avaliadas com base nas informações de Campbell (2005) sobre a compostagem. A maioria de cada um dos segmentos dessa comunidade definiu corretamente a composteira (Tabela 1). Uma parte descreveu os materiais utilizados ou fez alusão ao processo de compostagem em si. Portanto, pode-se considerar que a comunidade escolar tem conhecimento, em linhas gerais, do que é uma composteira e a sua finalidade.

Tabela 1. Frequência de respostas $(\%)$ dos diferentes segmentos da comunidade escolar à pergunta "O que é composteira?"

\begin{tabular}{|c|c|c|c|c|}
\hline \multirow[b]{2}{*}{ Respostas } & \multicolumn{4}{|c|}{ Frequência (\%) } \\
\hline & $\begin{array}{l}\text { Orientadores } \\
\text { pedagógicos }\end{array}$ & Professores & $\begin{array}{l}\text { Funcio- } \\
\text { nários }\end{array}$ & $\begin{array}{l}\text { Pais de } \\
\text { alunos }\end{array}$ \\
\hline $\begin{array}{l}\text { Definiram como local/recipiente onde acontece o } \\
\text { processo de compostagem }\end{array}$ & 100 & 66,7 & 83,3 & 72,0 \\
\hline $\begin{array}{l}\text { Definiram como processo de } \\
\text { reutilização/transformação de resíduos orgânicos }\end{array}$ & 0 & 20,0 & 0 & 24,0 \\
\hline $\begin{array}{l}\text { Descreveram materiais ou conjunto de elementos } \\
\text { utilizados no processo de compostagem }\end{array}$ & 0 & 13,3 & 16,7 & 0 \\
\hline Outras & 0 & 0 & 0 & 4,0 \\
\hline
\end{tabular}

Em relação à questão 2 - “Como você montaria uma composteira?”, $100 \%$ dos orientadores pedagógicos participantes mencionaram resíduos disponíveis na escola ou a montagem do suporte para a compostagem, escrevendo frases como: - deveria montar no chão, cavando um buraco ou reaproveitar lixeiras danificadas. Entretanto, respostas de natureza semelhante foram dadas por cerca de $52 \%$ dos pais, $46 \%$ dos professores e somente $17 \%$ dos funcionários. Esses três grupos revelaram outras preocupações na montagem da composteira, como o tamanho e a sua propocionalidade em relação ao resíduo disponível e a escolha dos resíduos adequados, que foi manifestada por $20 \%$ dos professores. Cerca de $13 \%$ dos professores e $4 \%$ dos pais mencionaram a necessidade de orientações e palestras. Portanto, a maioria não revelou a necessidade de atividades desse tipo. Outras respostas desses dois grupos mencionaram parceria com alunos, professores e pais para formação de composteiras. A maioria dos funcionários (cerca de 84\%) expressou a importância da montagem da composteira em espaço ou área afastada, revelando um conhecimento prático e preocupação com a higiene e a ordem geral da escola. Essa preocupação foi manifestada por somente $7 \%$ dos professores e $20 \%$ dos pais.

Na questão 3 - "O que você acha que pode ser feito com a composteira", a maioria de cada um dos segmentos da comunidade escolar indicou a produção de adubo para ativar a horta escolar. Essa resposta foi dada por $100 \%$ dos funcionários, $80 \%$ dos professores, $67 \%$ dos orientadores pedagógicos e $56 \%$ dos pais de alunos. O aproveitamento dos resíduos e a utilidade didática foram mencionados por $33 \%$ dos orientadores pedagógicos, $20 \%$ dos 
professores e $28 \%$ dos pais. Portanto, a maioria da comunidade escolar não considerou a atividade de compostagem como uma estratégia pedagógica e isso requer uma discussão mais aprofundada, principalmente com os funcionários.

$\mathrm{O}$ uso pedagógico da composteira foi explicitamente perguntado aos participantes na questão 4 - "Você acha que a composteira poderia ser utilizada nas aulas? De que modo?". A maioria dos orientadores pedagógicos (67\%) apontou a implementação de um projeto interdisciplinar ou que a composteira poderia ser utilizada para abordar conteúdos de várias disciplinas. A maioria dos funcionários $(67 \%)$ e $47 \%$ dos professores apontou o uso nas aulas de Ciências e disciplinas afins. Portanto, os orientadores pedagógicos vislumbraram a atividade de compostagem como um instrumento para abordar a questão ambiental de modo interdisciplinar. Entretanto, funcionários e professores mostraram uma visão mais restrita e consideraram que a composteira deve ser explorada pela disciplina de Ciências e afins. A maioria dos pais de alunos não mencionaram quais disciplinas específicas poderiam utilizar a composteira, mas $44 \%$ deles mencionaram aulas que abordem a educação ambiental e expressaram termos como sustentabilidade, responsabilidade e consciência ambiental em suas respostas. Portanto, isso revela que menos da metade dos pais associaram a atividade de compostagem com a educação ambiental num sentido mais amplo. Cerca de $33 \%$ dos professores e $28 \%$ dos pais mencionaram aulas de montagem da composteira para acompanhamento e estudo do processo de compostagem. Portanto, essas respostas sugerem que uma parcela não desprezível da comunidade escolar não tem clareza do potencial pedagógico da compostagem, além do que se pode aprender sobre a compostagem em si. Além disso, estes dados evidenciam certa dificuldade em concretizar a EA transversal e interdisciplinar na prática pedagógica. Segundo Tozoni-Reis e Campos (2014) essa dificuldade dos professores está relacionada à sua formação, enquanto educadores ambientais. Essa dificuldade foi também percebida por Mello Filho (2014) que executou projetos de compostagem em escolas do Paraná.

Com relação à questão 5 -"Você acha que a composteira traria algum inconveniente para você, os alunos ou a escola?", $73 \%$ dos participantes da pesquisa afirmaram que a composteira não traria inconvenientes para ele mesmo, para os alunos e para a escola. Cerca de $27 \%$ dos professores e $20 \%$ dos pais afirmaram que haveria incovenientes se as normas técnicas não fossem respeitadas, que incluiriam cuidados na montagem e proteção da composteira para evitar o mau cheiro, a atração ou a proliferação de insetos. Os demais que mencionaram inconveniências afirmaram que isso ocorreria se a composteira ficasse em local inadequado.

\subsection{Análise dos desenhos}

\subsubsection{Categoria - Conhecimento sobre a composteira}

Embora 49 indivíduos tenham feito o desenho, respondendo à solicitação "faça um desenho demonstrando como você imagina uma composteira na escola", um deles não representou propriamente uma composteira. Portanto, 48 desenhos restantes foram analisados e observou-se uma variedade de seus tipos (Tabela 2).

A composteira em forma de canteiro foi a representação mais frequente para cerca de $27 \%$ de todos os participantes da pesquisa, seguida da representação de recipientes plásticos. Em 8,4\% dos desenhos, a composteira foi representada sobre uma base sólida. Em um desses desenhos foi também representada uma drenagem do chorume. Este tipo de composteira figura entre os mais práticos, pois facilita a construção da pilha de resíduos e o revolvimento dos mesmos durante a decomposição, além de evitar o acúmulo de chorume.

Os locais em que as composteiras foram representados foram também analisados, sendo que $77 \%$ dos desenhos as representaram em locais expostos ao sol, chuvas e ventos. Cerca de 
$17 \%$ dos desenhos representaram a composteira à sombra de árvores, e, uma pequena minoria (6\%) em locais protegidos por toldos, cabanas e casas. Esse último grupo pode não estar ciente da importância da aeração da composteira, ou pensaram na vermicompostagem ou minhocário, que frequentemente requer uma tampa.

Tabela 2. Frequência (\% em relação ao total de desenhos) dos tipos de composteiras representadas pelos diferentes segmentos da comunidade escolar.

\begin{tabular}{llllll}
\hline \multirow{2}{*}{ Tipos de Composteiras } & \multicolumn{5}{c}{ Frequência (\%) } \\
\cline { 2 - 5 } & $\begin{array}{l}\text { Orientadores } \\
\text { pedagógicos }\end{array}$ & Professores & Funcionários & $\begin{array}{c}\text { Pais de } \\
\text { Alunos }\end{array}$ & Total \\
\hline $\begin{array}{l}\text { Forma de canteiro (com } \\
\text { cercado e no chão) }\end{array}$ & 2,1 & 6,2 & 4,2 & 14,6 & 27,1 \\
$\begin{array}{l}\text { Suporte plástico: tonéis, } \\
\text { baldes, bacias, garrafas PET }\end{array}$ & 2,1 & 4,2 & 0 & 14,6 & 20,9 \\
Estrutura de madeira & 0 & & & & \\
& 8,3 & 2,1 & 8,3 & 18,7 \\
Buraco, cova, direto no chão & 2,1 & 6,2 & 2,1 & 6,2 & 16,6 \\
Base sólida & 0 & 2,1 & 2,1 & 4,2 & 8,4 \\
Outros & 0 & 4,2 & 0 & 4,2 & 8,4 \\
\hline
\end{tabular}

Os tipos de resíduos representados na composteira foram de origem vegetal como folhas, ramos, galhos frescos ou em decomposição. Esse tema foi desenhado por todos os orientadores pedagógicos, por cerca de $47 \%$ dos professores, $67 \%$ dos funcionários e por $44 \%$ de pais de alunos. Por outro lado, $13 \%$ dos professores, $16 \%$ dos funcionários e $4 \%$ dos pais representaram resíduos vegetais, incluindo cascas e caroços, juntamente com restos de merenda e comida. Portanto, há um grupo de pessoas na comunidade que pode ter a expectativa de compostar todos os resíduos orgânicos da escola. Somente $8 \%$ dos pais cometeram equívocos representando resíduos compostáveis com materiais não compostáveis (plástico e pedras) ou fez a representação de material compostável com material reciclável (papel e papelão). Isso sugere que esclarecimentos devem ser feitos à comunidade, de que nem tudo pode ser adicionado à composteira e que alguns materiais podem ser destinados a outros métodos de reciclagem.

Somente $14 \%$ dos desenhos continham animais, tendo sido retratadas moscas e minhocas na composteira. As moscas sinalizavam mau cheiro e as minhocas sugerem a importância delas na decomposição orgânica, tornando mais rico em nutrientes o composto que está sendo produzido.

A representação ou referências ao chorume foi observada em cerca de $10 \%$ dos desenhos. Um dos pais recomendou, em texto no próprio desenho, que este líquido produzido durante o processo de decomposição dos resíduos fosse aproveitado como biofertilizante.

\subsubsection{Categoria - Composteira como solução ambientalmente correta para os resíduos orgânicos gerados na escola}

A representação de ambientes limpos e organizados, nos quais a composteira estava compondo os cenários (Figura 1), foi observado em $65 \%$ do total de desenhos. Esse tipo de desenho foi feito por $100 \%$ dos orientadores pedagógicos, $76 \%$ dos pais, $60 \%$ dos professores e $17 \%$ dos funcionários que participaram da pesquisa. Portanto, é razoável supor que a maior 
parte da comunidade escolar, exceto os funcionários, considera que a composteira poderia ser uma solução para os resíduos orgânicos produzidos na escola. Na questão 3 do questionário, $100 \%$ dos funcionários responderam que usariam a composteira para produção de adubo para ativar a horta escolar. Portanto, é possível que esse segmento não tenha clareza das implicações da compostagem na saúde ambiental, mas atenha-se aos seus benefícios práticos como obtenção de adubo para horta.

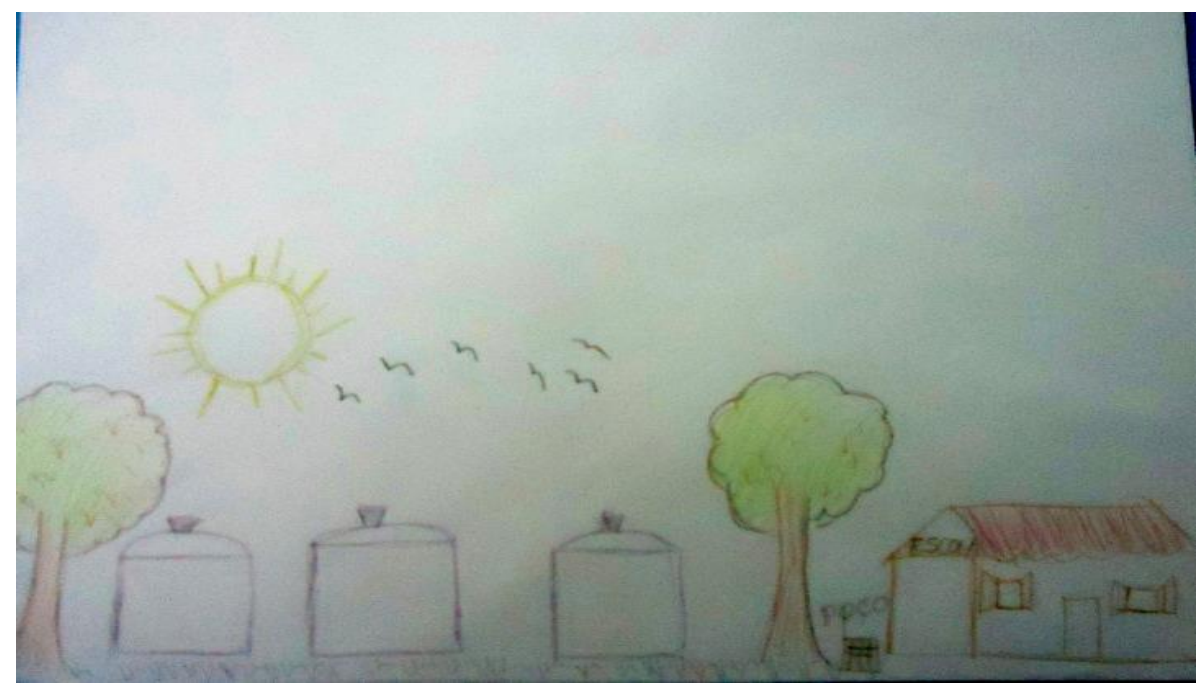

Figura 1. Uma das representações de um ambiente limpo, organizado, com as composteiras compondo o cenário.

\subsubsection{Categoria - Compostagem na atividade escolar como indicadora de Educação Ambiental}

Verificou-se que dos 49 desenhos feitos pelos participantes havia a presença da figura humana em 12 deles ( $25 \%$ do total). Esse tipo de desenho foi feito por $67 \%$ dos orientadores pedagógicos, $28 \%$ dos pais e $20 \%$ dos professores. Nenhum dos funcionários representou a figura humana.

Na Figura 2, encontra-se a representação de diferentes cenas na área verde da escola com a presença de figura humana: o professor e os alunos envolvidos em atividades nas proximidades da composteira; os alunos colocando adubo nas árvores sob a supervisão da professora; a hora do recreio, quando os alunos jogam bola e brincam de pular corda e em roda de conversa. O cenário, como um todo, retrata uma escola que tornou as questões ambientais, como a geração de resíduos orgânicos, em possibilidades de aprendizagens e de cuidados e respeito com o meio ambiente. Observa-se também que os ambientes bem cuidados promovem interações agradáveis de lazer e de harmonia com a natureza.

A Política Nacional de Resíduos Sólidos, Lei nº12.305/2010, Cap. III. Art. 8, indica a EA como instrumento destinado a promover a não geração, a redução, a reutilização e a reciclagem dos resíduos sólidos (Brasil, 2010). A EA de acordo com lei $\mathrm{n}^{\circ}$ 9.795/99, da Política Nacional de Educação Ambiental, no artigo $1^{\circ}$ é compreendida como processos por meio dos quais o indivíduo e a coletividade constroem valores sociais, conhecimentos, habilidades, atitudes e competências voltadas para a conservação do meio ambiente, bem comum do povo, essencial à sadia qualidade de vida e sua sustentabilidade (Brasil, 1999). Jacobi (2002, p. 94) recomenda que a EA: "deve ser vista como um processo de permanente aprendizagem, que valoriza diversas formas de conhecimentos e forma cidadãos com consciência local e planetária".

Neste contexto a compostagem se apresenta como possibilidade sustentável para a ETRB, pois reduzirá a grande quantidade dos resíduos orgânicos vegetais; produzirá um 
adubo de boa qualidade, que poderá ser utilizado para reativar a horta escolar e adubar as plantas que se encontram nas dependências da escola; e, do ponto de vista pedagógico, permitirá a inclusão da EA no currículo. Uma estimativa preliminar da quantidade de resíduos vegetais produzidos na área verde da ETRB foi realizada. Em 7 dias de coleta foram recolhidos 389,9 $\mathrm{kg}$ de massa fresca, que corresponderam a $16,35 \mathrm{~kg}$ de massa seca. Esses resultados indicaram que quase $3 \mathrm{t}$ de massa seca poderiam ser utilizadas para a compostagem durante um semestre. Há uma estimativa de que o rendimento da compostagem de material florestal pode ser de aproximadamente 50\% da massa inicial (Corradine, 2006). Portanto, pode ser possível que cerca 1,5 t de composto possa ser produzido, por semestre, na ETRB. Segundo Edwards e Araya (2011), em áreas úmidas da Etiópia, 5 a 8 t de composto aplicado por hectare melhoram a produtividade de colheitas agrícolas. Portanto, a quantidade produzida na ETRB poderia suprir uma área de 1875 a $3000 \mathrm{~m}^{2}$ por semestre considerando a proporção de $8 \mathrm{t} /$ ha e $5 \mathrm{t} / \mathrm{ha}$, respectivamente.

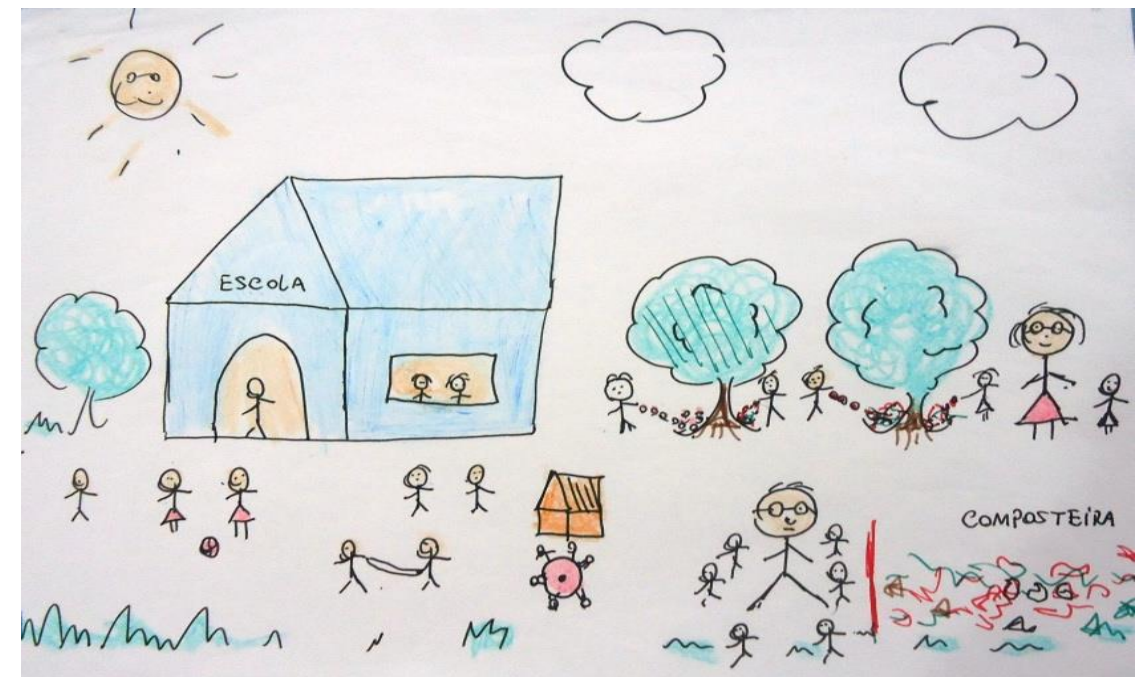

Figura 2. Desenho feito por um dos participantes da pesquisa, que foi enquadrada na categoria - compostagem na atividade escolar.

Um projeto pedagógico em EA, como o que se pretende desenvolver na ETRB, pode ser definido como uma metodologia de ensino que possibilita a integração de conteúdos de diferentes disciplinas em função de uma temática central. Este processo ocorre num contexto de diálogo, e de acolhida dos diferentes pontos de vista dos participantes, de modo que se consiga uma compreensão global do tema em questão (Santos et al., 2014).

$\mathrm{O}$ trabalho com projetos, enquanto metodologia de ensino se diferencia das formas tradicionais de ensino/aprendizagem, pois possibilita aos estudantes saber formular questões, investigar, localizar as fontes de informação, utilizar instrumentos e estratégias que lhes permitam elaborar as informações coletadas, a saber, eleger o que é relevante para encontrar possíveis soluções para o problema proposto. Portanto, fomenta a participação mais ativa e autônoma dos estudantes na construção de suas aprendizagens (Behrens e Zem, 2007).

Os objetivos da EA incluem "Sensibilização Ambiental" (processo de alerta, considerado como o primeiro passo no processo da EA, efetivadas na forma de visitas a lixões, matas ciliares, bosques, etc.); "Compreensão Ambiental" (conhecimento dos componentes e dos mecanismos que regem a natureza); "Responsabilidade Ambiental" (reconhecimento do ser humano como principal protagonista para determinar e garantir a manutenção do planeta); e "Competência e Cidadania Ambiental" (capacidade de avaliar e agir efetivamente no 
ambiente e capacidade de participar ativamente, resgatando os direitos e promovendo uma ética capaz de conciliar a natureza e sociedade) (Abreu et al., 2008).

Para que o projeto da composteira na ERTB seja realmente trabalhado de forma interdisciplinar e transversal, com continuidade e em vários anos de ensino, há a necessidade de se planejar as ações para que os quatro objetivos acima citados sejam alcançados até o final do ciclo educacional.

Nos momentos iniciais do projeto poderão ser realizadas atividades que promovam a sensibilização e a compreensão ambiental, tais como visitas ao aterro sanitário que se encontra na região metropolitana de Belém (PA). A visita deve conduzir a atividades posteriores de informação/discussão sobre os problemas ambientais relacionados à disposição inadequada dos resíduos orgânicos, sobre a composteira e os benefícios socioambientais, econômicos e pedagógicos que poderão ser obtidos através desta técnica.

Outras atividades sugeridas, visando os demais objetivos da EA, acima mencionados, encontram-se no Quadro 3, sendo que algumas delas já foram realizadas em escolas que executaram o projeto de compostagem ou outros projetos relativos à EA.

As atividades indicadas nos Quadros 3, 4 e 5 poderão ser desenvolvidas, com o acompanhamento/orientação dos professores, por estudantes do Ensino Fundamental I (EFI) turmas do $4^{\mathrm{o}}$ e $5^{\mathrm{a}}$ anos, do Ensino Fundamental II (EFII) e Ensino Médio (EM).

Quadro 3. Atividades interdisciplinares sugeridas para o desenvolvimento do projeto de compostagem na escola, na etapa de iniciação da composteira.

\begin{tabular}{|c|c|}
\hline Disciplina & Atividade com os alunos \\
\hline Matemática & $\begin{array}{l}\checkmark \text { Determinação da massa e volume de resíduos vegetais produzidos na área } \\
\text { verde da escola (EFI, EFII e EM). } \\
\checkmark \text { Estimativa da área necessária, considerando o volume de resíduos produzidos } \\
\text { (SANCHES et al, 2006) (EFI, EFII e EM). } \\
\checkmark \text { Medida do perímetro e cálculo da área da composteira. (EFI, EFII e EM). }\end{array}$ \\
\hline $\begin{array}{l}\text { Geografia } \\
\text { Ciências Naturais } \\
\text { Matemática }\end{array}$ & $\begin{array}{l}\checkmark \text { Construção de pluviômetros caseiros a serem colocados na área da } \\
\text { composteira, para estimativa de chuvas e volume de água que cairá sobre a } \\
\text { composteira (EFI e EFII). }\end{array}$ \\
\hline
\end{tabular}

Quadro 4. Atividades interdisciplinares sugeridas para o desenvolvimento do projeto de compostagem na escola, na etapa de montagem e manutenção da composteira.

\begin{tabular}{|ccl|}
\hline Disciplina & \multicolumn{1}{c|}{ Atividade com os alunos } \\
& $\checkmark$ & $\begin{array}{l}\text { Coleta de folhas com observação das espécies de árvores que as produzem. Analisar uma } \\
\text { amostra de folhas secas, identificando quais espécies perdem mais folhas. Construção de } \\
\text { tabelas e gráficos para apresentação dos resultados (EFI e EFII). }\end{array}$ \\
& $\checkmark$ & $\begin{array}{l}\text { Reviramento do material a ser compostado, observando as alterações. Discutir o papel dos } \\
\text { decompositores e animais que eventualmente surjam no local (EFI, EFII e EM). }\end{array}$ \\
& $\checkmark$ & $\begin{array}{l}\text { Medida da variação do pH do material compostado ao longo do tempo, discutindo o conceito } \\
\text { de pH e as causas de sua variação (Sanches et al, 2006) (EFII e EM). }\end{array}$ \\
& $\checkmark$ & $\begin{array}{l}\text { Medidas de temperatura ao longo do tempo, discutindo o significado dessas mudanças no } \\
\text { processo da compostagem (Silva et al., 2015). (EFI, EFII e EM). }\end{array}$ \\
Niências & $\checkmark$ & $\begin{array}{l}\text { Determinação do teor de umidade do composto, que pode ser feito com o uso de uma estufa } \\
\text { de secagem/forno de microondas em potência média (método descrito por Pastorini et al., }\end{array}$ \\
& & $\begin{array}{l}\text { 2002) e balança. Discutir o significado do teor de umidade e sua relação com o metabolismo } \\
\text { aeróbio e anaeróbio dos microrganismos (EFII e EM). }\end{array}$ \\
& $\checkmark$ & $\begin{array}{l}\text { Rega do material a ser compostado, registro de volume de água utilizado por rega e relacionar } \\
\text { com o índice pluviométrico da área da composteira (EFI, EFII e EM). }\end{array}$ \\
Geografia & &
\end{tabular}


Quadro 5. Atividades interdisciplinares sugeridas para o desenvolvimento do projeto de compostagem na escola, na etapa de acabamento da compostagem.

\section{Disciplina}

Matemática

Ciências Naturais

Ciências Naturais

Língua Portuguesa

Língua

Estrangeira

Ciências Naturais

Artes

Língua Portuguesa

História

Ciências Sociais

Artes

\section{Atividade com os alunos}

$\checkmark$ Atividade de peneiramento e pesagem do composto formado. Cálculo de rendimento da compostagem (EFI, EFII e EM).

$\checkmark$ Comparação da permeabilidade de diferentes tipos de solos da área da escola, incluindo o do solo com composto adicionado (EFII e EM).

$\checkmark$ Plantio de vegetais de rápido crescimento em solo com e sem composto adicionado para comparação do crescimento. Medidas de crescimento (altura da planta, largura e comprimento das folhas, etc.) podem ser realizadas para discutir o efeito do composto ${ }^{1}$ (EFI, EFII e EM).

$\checkmark$ Redação (dissertação) e relatórios sobre a atividade de compostagem e, dependendo da série, com produção de tabelas e gráficos (EFI, EFII e EM).

$\checkmark$ Criação de cartazes ou relatórios ilustrados, retratando a atividade de compostagem na escola destacando a importância da atividade para o meio ambiente e a sociedade. Destacar o volume de material orgânico da escola que evitou-se enviar para os vazadouros a céu aberto (EFI, EFII e EM).

$\checkmark$ Breve histórico da criação do método de compostagem (Hershey, 1992) e discussão das razões de sua pouca empregabilidade nas cidades de maneira geral, abordando a origem da poluição ambiental, as razões econômicas e sociais (desperdício, consumismo, etc.) (EFI, EFII e EM).

$\checkmark$ Júri simulado (Albuquerque et al., 2015) ou dramatizações para debater por que a coleta seletiva não é realizada na maioria das cidades brasileiras, procurando convidar pais de alunos e a comunidade para as apresentações, os quais devem também ser incentivados a refletir e expressar suas conclusões sobre o seu papel no meio ambiente e na preservação deste (EFII e EM).

\footnotetext{
${ }^{1}$ Os professores não devem temer resultados negativos ou inesperados nos experimentos. Devem incentivar a busca por respostas e a criação de hipóteses razoáveis que expliquem os resultados. Essa postura é mais importante para a educação científica do estudante do que os próprios resultados dos experimentos.
}

\section{CONCLUSÃO}

Os membros da comunidade escolar têm conhecimento básico sobre a compostagem. Eles reconhecem, na sua maioria, que este recurso não traria inconveniente para a escola, mas traria benefícios, progresso para a comunidade escolar, para a educação, a cidadania e o respeito ao meio ambiente. O grande interesse e aprovação dos participantes deste estudo demonstra que o projeto deve ser apresentado à toda comunidade, mostrando os objetivos que se pretende alcançar dentro da educação ambiental. No que se refere à interdisciplinaridade e à transversalidade, verificou-se que se faz necessário uma profunda discussão e reflexão entre os professores, pois serão eles que irão propor e coordenar as atividades práticas dos alunos. A seleção das atividades e os conteúdos que podem ser abordados através da compostagem devem compor a próxima etapa da elaboração do projeto, bem como a definição dos critérios de avaliação após sua execução. 


\section{REFERÊNCIAS}

ABREU, D. G.; CAMPOS, M. L.; AGUILAR, M. Educação ambiental nas escolas da região de Ribeirão Preto (SP): concepções orientadoras da prática docente e reflexões sobre a formação inicial de professores de Química. Química Nova, v. 31, n. 3, p. 688-693, 2008. http://dx.doi.org/10.1590/S0100-40422008000300037

ALBUQUERQUE, C.; VICENTINI, J. O.; PIPITONE, M. A. P. O júri simulado como prática para a educação ambiental crítica. Revista Brasileira de Estudos Pedagógicos, v. 96, n. 242, p. 199-215, 2015.

BARDIN, L. Análise de conteúdo. São Paulo: Edições 70, 2011.

BEHRENS, M. A.; ZEM, R. A. M. S. Metodologias de projeto: o processo de aprender a aprender. In: TORRES, P. L. (Org.). Algumas vias para entretecer o pensar e o agir. Curitiba: SENAR/PR, 2007. p. 38-65.

BOTH, J. P. C. L.; SENNA, R. R. Compostagem orgânica: "Fazer para Aprender", uma experiência de ensino aprendizagem na Escola Bosque Professor Eidorfe Moreira, Belém/PA. Revista Brasileira de Agroecologia, v. 4, n. 2, p. 929-930, 2009.

BRASIL. Ministério da Educação. Parâmetros Curriculares Nacionais: apresentação dos temas transversais e ética. Brasília, DF: MEC/SEF, 1997a.

Parâmetros Curriculares Nacionais: meio ambiente, saúde. Brasília, DF: MEC/SEF, 1997b.

. Parâmetros Curriculares Nacionais: ciências naturais. Brasília, DF: MEC/SEF, 1998.

BRASIL. Lei no 9.795, de 27 de abril de 1999. Dispõe sobre a educação ambiental, institui a Política Nacional de Educação Ambiental e dá outras providências. Diário Oficial [da] União, Brasília, DF, 28 abr. 1999.

. Lei $\mathrm{n}^{\circ}$ 12.305, de 2 de agosto de 2010. Institui a Política Nacional de Resíduos Sólidos; altera a Lei no 9.605, de 12 de fevereiro de 1998; e dá outras providências. Diário Oficial [da] União, Brasília, DF, 3 ago. 2010.

CAMPBELL, S. Deixe apodrecer! Manual de compostagem: a reciclagem natural na horta e no jardim. Portugal: Publicações Europa-América; LDA, 2005.

CORRADINE, L. Manejo e operação da central de compostagem na Votorantim Celulose e Papel SA. In: SIMPÓSIO SOBRE USO DE BIOSSÓLIDOS EM PLANTAÇÕES FLORESTAIS, 13., 2006, São Paulo. Anais... São Paulo: IPEF, 2006.

EDWARDS, S.; ARAYA, H. How to make and use compost. In: CHING, L. L.; EDWARDS, S.; SCIALABBA, N. El-H. (Ed.). Climate change and food systems resilience in Sub-Saharan Africa. Rome: FAO, 2011. p. 379-476.

HERSHEY, D. Sir Albert Howard and the Indore process. HortTechnology, v. 2, n. 2, p. 267-269, 1992.

JACOBI, P. A importância do meio ambiente na construção da cidadania. In: MARFAN, M. A. (Org.). Congresso Brasileiro de Qualidade na Educação: formação de professores: educação ambiental. Brasília, DF: MEC, 2002. v. 3. p. 92-98. 
MELLO FILHO, N. R. Aplicação e avaliação de técnicas de agroecologia e compostagem como dinamizadores da educação ambiental nos currículos e espaços escolares. 2014. 187 f. Dissertação (Mestrado em Ciência e Tecnologia Ambiental) - Programa de Pós-Graduação em Ciência e Tecnologia Ambiental, Universidade Tecnológica Federal do Paraná, Curitiba, 2014.

PASTORINI, L. H.; BACARIN, M. A.; ABREU, C. M. Secagem de Material vegetal em forno de micro-ondas para determinação de matéria seca e análise química. Ciência e Agrotecnologia, v. 26, n. 6, p. 1252-1258, 2002.

SANCHES, S. et al. A importância da compostagem para a educação ambiental nas escolas. Química Nova na Escola, v. 23, p. 10-13, 2006.

SANTOS, A. Ensino integrado: justaposição ou articulação? In: SANTOS, A.; SOMMERMAN, A. (Org.). Ensino disciplinar e transdisciplinar: uma coexistência necessária. Rio de Janeiro: Wak, 2014.

SEVERINO, A. J. Metodologia do trabalho científico. 23. ed. rev. e atual. São Paulo: Cortez, 2007.

SILVA, M. A. et al. Compostagem: experimentação problematizadora e recurso interdisciplinar no ensino de Química. Química Nova na Escola, v. 37, n. 1, p.71-81, fev. 2015. http://dx.doi.org/10.5935/0104-8899.20150011

TOZONI-REIS, M. F. C.; CAMPOS, L. M. L. Educação ambiental escolar, formação humana e formação de professores: articulações necessárias. Educar em Revista, Edição Especial, n. 3, p. 145-162, 2014. http://dx.doi.org/10.1590/0104-4060.38112 